\title{
NLRP3 Inflammasome Pharmacological Inhibitors in Glycyrrhiza for NLRP3-Driven Diseases Treatment: Extinguishing the Fire of Inflammation
}

\author{
Zhilei Wang' \\ Guang $X^{2,3}$ \\ Zhiyong $\mathrm{Li}^{4}$ \\ Xiaohe Xiao $\mathbb{D}^{2,3}$ \\ Jianyuan Tang' \\ Zhaofang $\mathrm{Bai}^{2,3}$
}

'TCM Regulating Metabolic Diseases Key Laboratory of Sichuan Province, Hospital of Chengdu University of Traditional Chinese Medicine, Chengdu, People's Republic of China; ${ }^{2}$ Senior Department of Hepatology, The Fifth Medical Centre of PLA General Hospital, Beijing, People's Republic Of China; ${ }^{3}$ China Military Institute of Chinese Materia, The Fifth Medical Centre of PLA General Hospital, Beijing, People's Republic of China; ${ }^{4}$ State Key Laboratory of Southwestern Chinese Medicine Resources, Chengdu University of Traditional Chinese Medicine, Chengdu, People's Republic of China

Correspondence: Jianyuan Tang;

Zhaofang Bai

Email tangjianyuan163@I63.com;

baizf2008@hotmail.com

\begin{abstract}
Inflammation is the tissues' defense response after the body is stimulated by microbial infection or damage signals, and it is initiated when pattern recognition receptors recognize pathogen-related molecular patterns and danger-related molecular patterns. The hyperactivation of NLRP3 inflammasome, the main driving force of immune outbreaks, is involved in a wide range of inflammatory diseases. Meanwhile, growing evidence has indicated that the development of NLRP3-targeted therapies offers great potential and promise for the treatment of related diseases. The search for and development of efficacious anti-inflammatory prodrugs from natural sources of plants and traditional Chinese medicines (TCMs) have received extensive attention. Glycyrrhiza, an important minister in the kingdom of TCMs, has high activity and a wide range of therapeutic effects. Studies have shown that a variety of active components found in Glycyrrhiza, such as licochalcone A, echinatin, isoliquiritigenin, and glycyrrhizin, produce a wide range of anti-inflammatory effects by discouraging NLRP3 inflammasome activation. Here, we summarize the role and mechanism of the active ingredients in Glycyrrhiza that target the NLRP3 inflammasome and treat related inflammatory diseases. We describe a favorable approach for the development of natural, safe, and efficient drugs that exploit these naturally occurring active ingredients to treat NLRP3-driven diseases.
\end{abstract}

Keywords: NLRP3 inflammasome, Glycyrrhiza, inflammatory diseases, anti-inflammatory

\section{Introduction}

Inflammation is a tissue defense response after the body is stimulated by external microbial infection or by damage signals from itself. The pathological manifestations include tissue exudation, degeneration, and hyperplasia in the inflammatory area, and are characterized by redness, swelling, heat, pain, and dysfunction. The inflammatory response is initiated when cell surface or intracellular pattern recognition receptors (PRRs) recognize pathogen-related molecular patterns (PAMPs) and danger-related molecular patterns (DAMPs). ${ }^{1}$ Many common clinical diseases, such as cardiovascular diseases, autoimmune diseases, wound repair, are characterized by inflammation. ${ }^{2-4}$ In clinical treatment, anti-inflammatory drugs are the second largest class of drugs after anti-infective drugs; these drugs mainly consist of steroidal anti-inflammatory drugs and non-steroidal anti-inflammatory drugs. However, due to the strong adverse side-effects of many synthetic drugs, ${ }^{5}$ the search for and development of dependable and efficacious anti-inflammatory drugs from natural sources such as plants has received extensive attention. In 
particular, traditional Chinese medicines (TCMs), the quintessence of disease prevention and control in China for thousands of years, are a very important part of the world medicine treasury and play a vital role in inflammation.

Innate immunity plays an important role in the development of a variety of diseases by regulating the immune and inflammatory responses that depend on PRRs. NLRP3 inflammasome is part of the innate immune response and is activated in response to PAMPs or DAMPs, promoting the expression, maturation and release of multiple proinflammatory cytokines that trigger a cascade of inflammatory responses. Recent studies have shown that the activation of NLRP3 inflammasome is the main driving force behind excessive immune outbreaks. ${ }^{6-8}$ The aberration of NLRP3 inflammasome activation participate in the development of human diseases, such as metabolic pathologies, cardiovascular diseases, inflammatory issues, and neurologic disorders. ${ }^{9-11}$ Glycyrrhiza, also known as "Guo Lao" in Chinese, is an important minister in the kingdom of TCMs. It is not only the most commonly used TCM in tonics and food, but also one of the most important TCMs with high levels of activity and a wide range of therapeutic effects. A wide range of pharmacological effects makes Glycyrrhiza useful for treating multisystem inflammatory diseases, allergic diseases, and immunocompromised diseases. ${ }^{12-15}$ A variety of active components in Glycyrrhiza exert a wide range of antiinflammatory effects by inhibiting NLRP3 inflammasome. Therefore, in this review, we mainly focus on the role and mechanism of the active ingredients in Glycyrrhiza and how they target the NLRP3 inflammasome to treat related inflammatory diseases.

\section{The Activation of NLRP3 Inflammasome}

Inflammasomes are protein polymer complexes that coordinate the host's defense mechanism against pathogens and physiological abnormalities. The assembly of inflammasome complexes is initiated by the nucleotide-binding domain and leucine-rich repeat receptors (NLRs) or absent in melanoma 2 (AIM2) like receptors (AIM2-like receptors, ALRs), etc. ${ }^{16,17}$ NLRs and ALRs mediate the recognition of PAMPs and DAMPs during bacterial, viral, fungal and cellular damage. In most cases, activated NLRs and ALRs will recruit the dimeric protein of apoptosis-associated speck-like protein containing a caspase activation and recruitment domain (ASC) which participates in caspase-1 activation. ${ }^{18}$ NLRP3 (also called CIAS1, Cryopyrin, NALP3 or Pypaf1) is composed of an amino-terminal pyrin domain (PYD), nucleotide-binding and oligomerization domain (NOD), C-terminal leucinerich repeat domain. ${ }^{19-21}$ The activation of the canonical NLRP3 inflammasome requires the completion of two signals (Figure 1). Signal 1 (priming stage) is characterized by toll-like receptors (TLRs), NOD2, tumor necrosis factor receptor 1 (TNFR1), TNFR2, etc., that induce NF$\kappa \mathrm{B}-$ mediated precursor protein production, including NLRP3, pro-IL-1 $\beta$, and pro-IL-18. Signal 2 (activation stage) is the stage when a variety of PAMPs and DAMPs induce the assembly of the NLRP3 inflammasome complex (NLRP3-ASC-pro-caspase-1). Subsequently, pro-caspase-1 auto-cleaves to form active caspase-1, and caspase1 then cleaves and activates the precursor proteins pro-IL$1 \beta$ and pro-IL-18 into mature forms IL-1 $\beta$ and IL-18, which are secreted into the extracellular to participate in the subsequent inflammatory response. At the same time, the activation of NLRP3 inflammasome also leads to the occurrence of a programmed cell death, called pyroptosis.

\section{Pharmacological Inhibitors of NLRP3 Inflammasome in Glycyrrhiza Licochalcone A (Lico A)}

Lico A (Figure 2A) is a chalcone occurring in Glycyrrhiza that has a wide range of pharmacological activities, including anti-inflammatory, anti-tumor, and anti-bacterial. ${ }^{14}$ Here, we focus on the anti-inflammatory effect of Lico A via targeting NLRP3 inflammasome. Osteoarthritis (OA) is the most common arthritis in the elderly and is characterized by subchondral bone hyperplasia and articular cartilage degeneration, leading to the loss of joint function. $^{22,23}$ NLRP3 inflammasome is a potentially novel therapeutic target for the management of OA. ${ }^{24,25}$ In vitro, Lico A suppresses NLRP3 inflammasome activation and GSDMD expression in primary mouse OA chondrocytes via nuclear factor erythroid-2 related factor 2 (Nrf2)/heme oxygenase-1 (HO-1)/NF- $\mathrm{BB}$ axis (Figure 3), indicating that Lico A attenuates LPS-induced chondrocyte pyroptosis. ${ }^{26}$ In vivo, Lico A significantly attenuates the LPS-induced IL-1 $\beta$ and IL-18 protein expression in an air pouch mouse model. ${ }^{26}$ The above studies indicate that Lico A may have therapeutic potential in OA. 


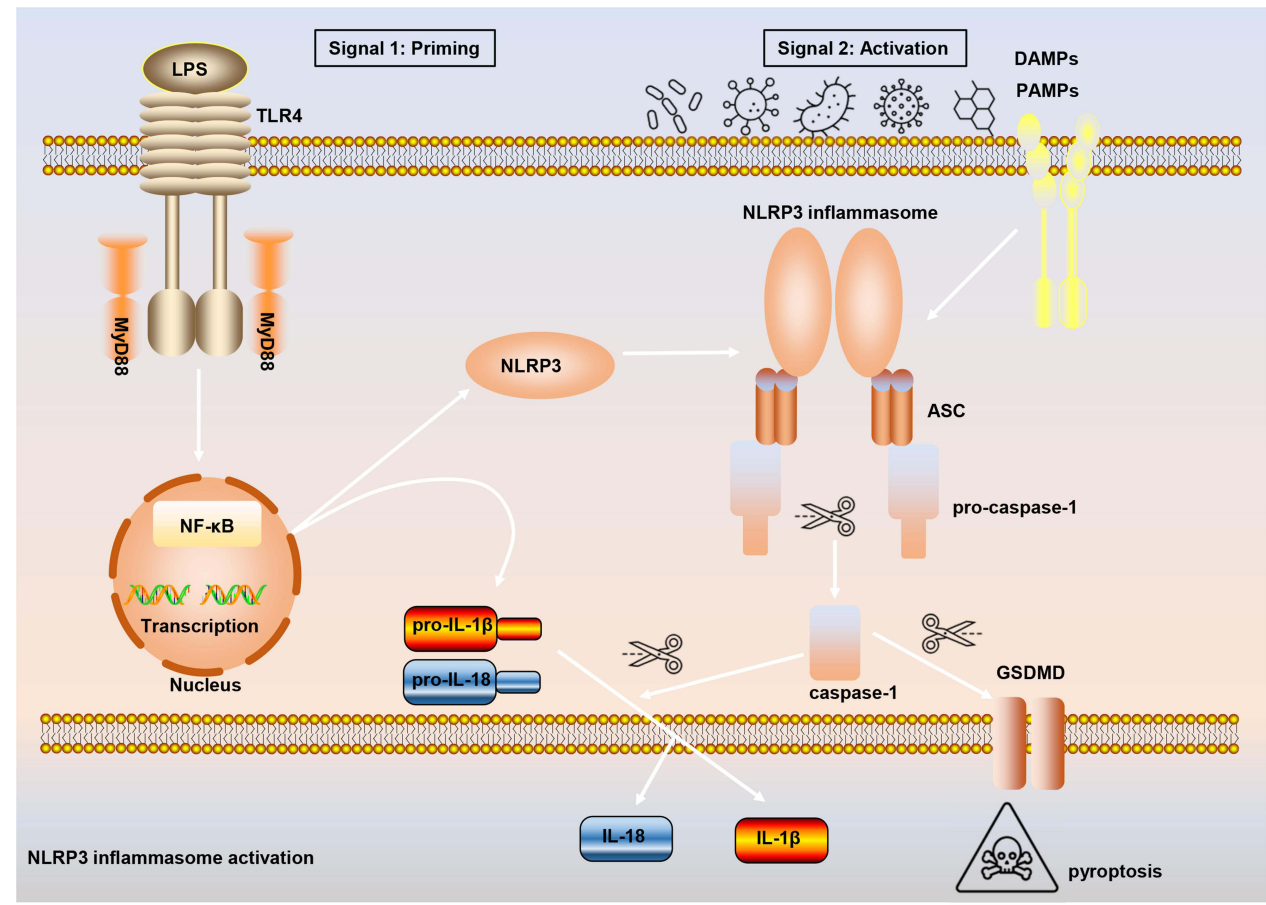

Figure I The process of canonical NLRP3 inflammasome activation. The priming signal (signal I) is provided by microbial components, such as lipopolysaccharide (LPS), leading to the activation of the transcription factor NF-KB and subsequent upregulation of NLRP3, pro-interleukin-I $\beta$ (pro-IL-I $\beta$ ), and IL-18. The activation signal (signal 2) is provided by a variety of stimuli including extracellular adenosine triphosphate (ATP), nigericin, pore-forming toxins, viruses et al, to induce the assembly of NLRP3-ASC-procaspase-I. Pro-caspase-I then auto-cleaves and activates the precursor proteins pro-IL-I $\beta$ and pro-IL-18 into mature forms IL-I $\beta$ and IL-I8. Moreover, active caspase-I also leads to the occurrence of pyroptosis.

A<smiles>C=CC(C)(C)c1cc(/C=C/C(=O)c2ccc(O)cc2)c(O)cc1OC</smiles>

Licochalcone A

D<smiles>COC1CC(O)CCC1/C=C/C(=O)c1ccc(O)cc1</smiles>

Echinatin

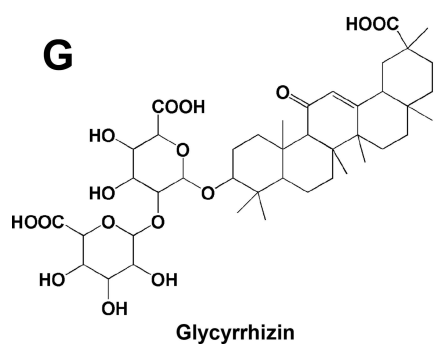

B<smiles>[B]c1ccc(C(=O)/C=C/c2ccc(O)c(O)c2OC)cc1</smiles>

Licochalcone B

E<smiles>O=C(/C=C/c1ccc(O)cc1)C1CCC(O)CC1O</smiles>

Isoliquiritigenin

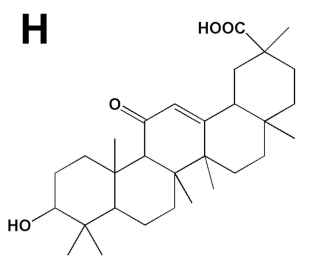

Glycyrrhetinic acid<smiles>COc1ccc2c(c1)OC(c1ccc(O)cc1)CC2=O</smiles>

Liquiritigenin

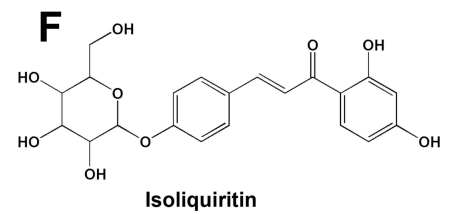

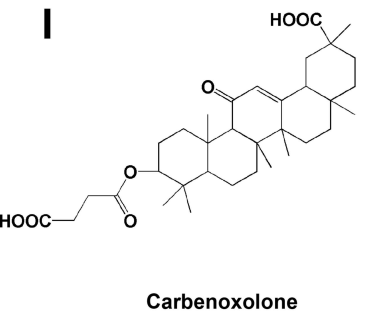

Figure 2 Chemical structure of compounds from Glycyrrhiza. (A) Licochalcone A; (B) Licochalcone B; (C) Liquiritigenin; (D) Echinatin; (E) Isoliquiritigenin; (F) Isoliquiritin; (G) Glycyrrhizin; (H) Glycyrrhetinic acid; (I) Carbenoxolone.

Cell stress causes excessive accumulation of reactive oxygen species (ROS), leading to the separation of thioredoxin interacting protein (Txnip) from thioredoxin-1 $\left(\right.$ Trx-1). ${ }^{27}$ Then, Txinp binds to NLRP3, triggering the activation of NLRP3 inflammasome, which has been proven to be a key signaling molecule connecting oxidative 


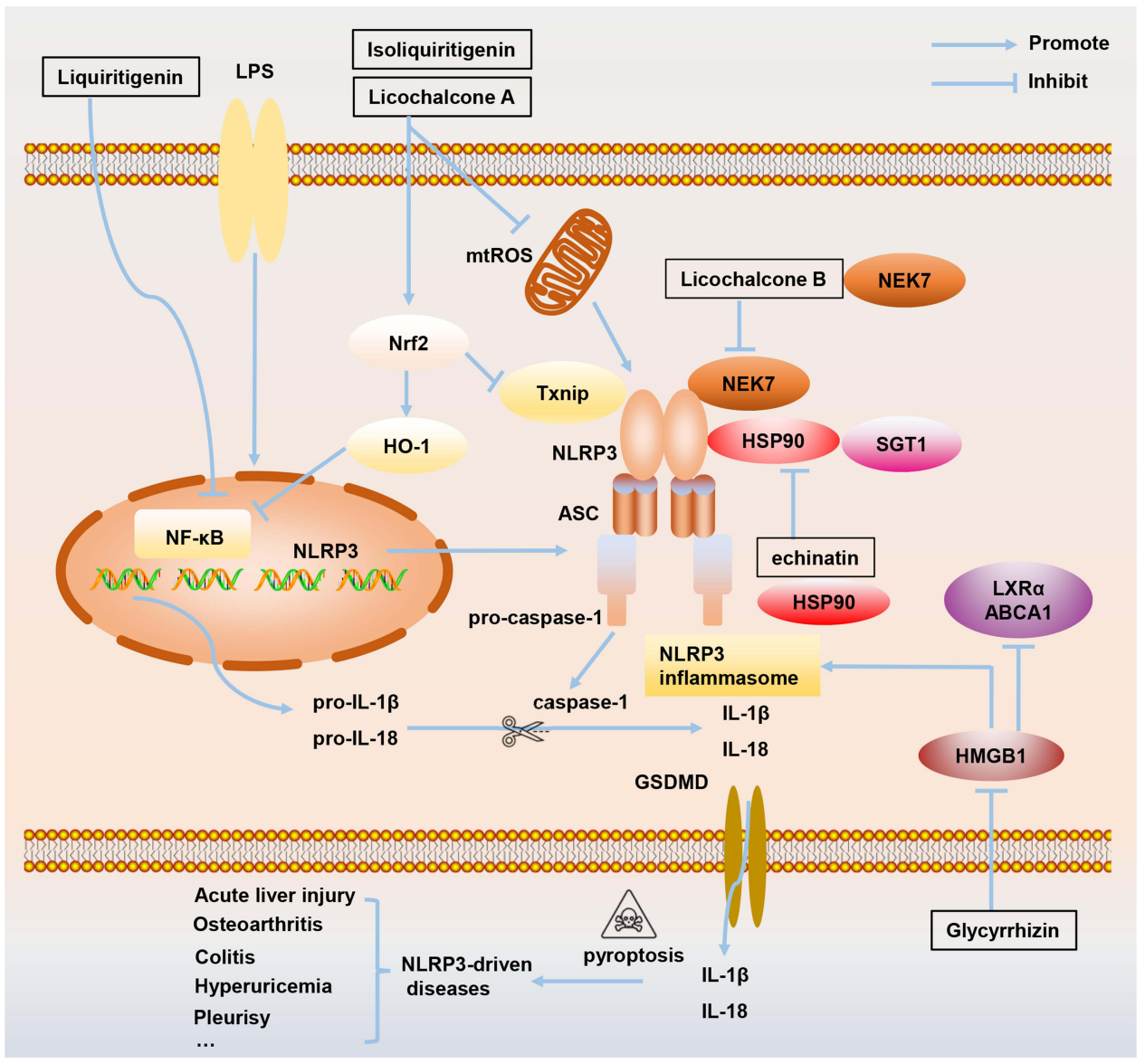

Figure 3 The mechanism of how active ingredients in Glycyrrhiza, including licochalcone A, licochalcone B, echinatin, liquiritigenin, isoliquiritigenin, and glycyrrhizin, target NLRP3 inflammasome to treat inflammation-related diseases.

Abbreviations: ABCAI, ATP-binding cassette transporter; HMGBI, High mobility group Box I; HO-I, Heme oxygenase-I;HSP90, Heat shock protein 90; LXR $\alpha$, liver X receptor $\alpha$; mtROS, Mitochondrial reactive oxygen species;NEK7, NIMA-related kinase 7; Nrf2, Nuclear factor erythroid 2-related factor 2; SGTI, Suppressor of G2 allele of skpl; Txnip, Thioredoxin-interacting protein.

stress and inflammasome activation. ${ }^{27,28}$ The LPS/GalNinduced inflammatory response is closely related to NLRP3 inflammasome activation. ${ }^{29-31}$ Studies have shown that Lico A treatment notably decreases Txnip, NLRP3, ASC, caspase-1 p20, and IL-1 $\beta$ p17 protein expression but enhances the expression of thioredoxin-1 (Trx-1) protein in LPS/GalN-induced acute lung injury (ALI) (Figure 3), ${ }^{32}$ indicating that inflammation inhibited by Lico A may be responsible for suppressing activation of the Txnip-NLRP3 inflammasome.

NLRP3 inflammasome activation triggered by Propionibacterium acnes (P. acnes) is vital for inducing inflammatory response and worsening the development of acne. $^{33-35}$ Lico A has been shown to suppress $P$. acneinduced NLRP3 inflammasome activation via inhibition of ASC speck formation and mitochondrial reactive oxygen species (ROS) in primary mouse BMDMs and immortalized human SZ95 sebocytes (Figure 3). ${ }^{36}$ Importantly, external use of Lico A on mouse ear skin reduces skin inflammation caused by $P$. acne, and blocks caspase-1 activity and IL- $1 \beta$ production. ${ }^{36}$ These results provide a theoretical basis for the development of natural, safe, and efficient health care products or drugs derived from Lico A raw materials.

\section{Licochalcone B (Lico B)}

Lico B is known to have strong pharmacological properties, such as anti-inflammatory, antibacterial, and anticancer. $^{14,37}$ Although the content of Lico B (Figure 2B) in Glycyrrhiza is relatively low, it has a strong anti-NLRP3 inflammasome effect. Our previous studies have shown that Lico B could specifically suppress NLRP3 inflammasome activation via binding to NEK7 and inhibiting the interaction between NLRP3 and NEK7 in BMDMs, THP-1 cells and human peripheral blood mononuclear cells $(\mathrm{PBMCs})^{38}$ (Figure 3 ). In vivo 
experiments show that Lico B ameliorates LPS-induced septic shock characterized by improving survival rate, inhibiting IL-1 $\beta$ production, reducing the number of peritoneal exudative cells and peritoneal macrophages; Meanwhile, MSU-induced peritonitis, and methionineand choline-deficient (MCD) diet-induced nonalcoholic steatohepatitis are significantly ameliorated by Lico B through targeting NLRP3 inflammasome. ${ }^{38}$ Taking these studies into consideration, we firmly believe that with further investigation of its pharmacological effects will lead to Lico B becoming a promising candidate in the treatment of NLRP3-related diseases.

\section{Liquiritigenin}

Hyperuricemia, a metabolic disease with a high prevalence rate, is typically related to high serum uric acid that could cause monosodium urate crystals to be deposited in the joints and kidneys, seriously endangering the life and health of patients. ${ }^{39,40}$ A large amount of evidence indicates that the inflammatory response mediated by the NLRP3 inflammasome plays a crucial role in the renal injury of rodent models for hyperuricemia and clinical patients. ${ }^{41-43}$ Liquiritigenin (Figure 2C), one of the flavonone compounds extracted from Glycyrrhiza plants, reduces the level of uric acid in the serum and urine, and decreases renal inflammation in potassium oxonateinduced hyperuricemic rats by inhibiting the activation of the renal AQP4/NF- $\kappa \mathrm{B} / \mathrm{I} \kappa \mathrm{B} \alpha$ signaling pathway and NLRP3 inflammasome. ${ }^{44}$ Hyperglycemia is considered a crucial element in the pathogenesis and progression of diabetic nephropathy (DN). ${ }^{45,46}$ Liquiritigenin suppresses high glucose-induced extracellular matrix accumulation, oxidative stress, and inflammation in the rat glomerular mesangial cell line HBZY-1 by inhibiting $\mathrm{NF}-\kappa \mathrm{B}$ and NLRP3 inflammasome pathways, ${ }^{47}$ thus showing potential for preventing the development of $\mathrm{DN}$.

\section{Echinatin}

Echinatin is a bioactive flavonoid in Glycyrrhiza. It has been reported that echinatin exhibits strong scavenging activity and suppresses the production of nitric oxide, interleukin-6 and prostaglandin E2 in LPS-induced macrophage cells. ${ }^{48}$ Moreover, echinatin could attenuate $\mathrm{CCl}_{4}{ }^{-}$ induced liver injury and may be responsible for the hepatoprotective activity of Glycyrrhiza. ${ }^{49}$ Our previous studies have shown that echinatin (Figure 2D) inhibits NLRP3 inflammasome activation by binding to heat-shock protein 90 (HSP90), inhibiting its ATPase activity and disrupting the association between the cochaperone SGT1 and HSP90-NLRP3 ${ }^{50}$ (Figure 3). In vivo experiments demonstrated that echinatin treatment could suppress NLRP3 inflammasome activation and ameliorate LPS-induced septic shock, dextran sodium sulfate-induced colitis, and MCD diet-induced nonalcoholic steatohepatitis in mice, ${ }^{50}$ making it a favorable candidate approach for therapeutic interventions in NLRP3 inflammasome-driven disease.

\section{Isoliquiritigenin (ILG)}

ILG (2',4',4'-trihydroxychalcone) (Figure 2E) is an isoflavone compound extracted from the Chinese herbal medicine Glycyrrhiza. It has been proven that ILG is biologically safe and has high levels of biological activity. Although Glycyrrhiza contains only low concentrations of ILG, ILG has a wide range of pharmacological properties, such as anti-inflammatory, anti-tumor, and antioxidant. ${ }^{51-53}$ In particular, the anti-inflammatory effect of ILG has been a rapidly growing research topic in recent years. Therefore, the following sections mainly explains the anti-inflammatory effect of ILG from the perspective of inhibiting NLRP3 inflammasome.

ILG plays a powerful role in repairing neuroinflammation damage. ILG pretreatment prevents cognitive impairment, reverses synaptic dysfunction, alleviates neuronal injury, attenuates microglia and astrocyte activation, and reduces the production of TNF- $\alpha$, IL- $1 \beta$, and IL-18 by promoting Nrf2 signaling and suppressing NLRP3 inflammasome activation in a kainic acid-induced seizure rat model. ${ }^{54}$ A study has shown that chronic nicotine exposure increases the protein levels of caspase-1, ASC, IL-1 $\beta$, and exacerbates ischemic brain damage via activation of the inflammasome in the brains of female rats. ${ }^{55}$ As an NLRP3 inflammasome inhibitor, ILG could decrease nicotineinduced ischemic neuronal death in hippocampal organotypic slice cultures after oxygen-glucose deprivation. ${ }^{55}$ Furthermore, spontaneous intracerebral hemorrhage $(\mathrm{ICH})$ is a fatal cerebrovascular disease that accounts for a relatively high proportion of all stroke types and is usually accompanied by high morbidity and mortality. ${ }^{56,57}$ ILG administration after collagenase IV-induced ICH decreases early brain impairments and neurological deficits, and the mechanism is related to triggering Nrf2 activity and Nrf2-induced antioxidant system to regulate the activation of NLRP3 inflammasome pathway ${ }^{58}$ (Figure 3). The results of this experiment also indicate that ILG is a potential drug candidate for a new treatment strategy for ICH. 
Organs and tissues are susceptible to self-injury or infection by foreign pathogens, and these lead to the occurrence of the inflammatory response. ILG can reduce the inflammatory response by inhibiting NLRP3 inflammasome activation, thus avoiding the occurrence of serious diseases. NLRP3 inflammasome and its regulatory mechanisms play an important role in the pathological process of ALI. ${ }^{59-61}$ By activating AMP-activated protein kinase (AMPK)/Nrf2/antioxidant response element (ARE) signaling and inhibiting the activation of NLRP3 inflammasome and NF- $\mathrm{KB}$ pathways, ILG significantly reduces lung injury in LPS-induced ALI mice, and it decreases the exudation of inflammatory cells and the levels of proinflammatory cytokines IL-1 $\beta$, IL- 6 , and TNF- $\alpha$ in bronchoalveolar lavage fluid, ${ }^{62}$ highlighting the beneficial effects of ILG and its related mechanisms in LPS-induced ALI and providing new insights for its application. Non-steroidal anti-inflammatory drug indomethacin could induce small intestinal damage and increase the protein levels of cleaved caspase- 1 and mature IL- $1 \beta$ in the small intestine.${ }^{63}$ ILG treatment improves indomethacin-induced small intestinal damage by suppressing NLRP3 inflammasome activation. ${ }^{63}$ Therefore, there is an urgent need to carry out relevant clinical studies to evaluate the effectiveness and safety of ILG in the treatment of intestinal diseases caused by non-steroidal anti-inflammatory drugs.

In addition, ILG also plays an important role in other inflammatory diseases. Chronic periodontitis is a common disease, and its incidence and severity increase with age. ${ }^{64}$ Periodontal ligament fibroblasts are the primary cell type in periodontal ligament tissues and play a vital role in the occurrence and development of periodontitis, including tissue repair and reconstruction. ${ }^{65,66}$ ILG markedly recovers the migration dysfunction induced by Porphyromonas gingivalis lipopolysaccharide by reducing NLRP3 inflammasome activation, caspase-1 activation, IL-1 $\beta$ and HMGB1 release in cultured mouse periodontal ligament fibroblasts. ${ }^{67}$ Pleurisy refers to inflammation of the pleura caused by a variety of infectious and noninfectious factors such as tumors, allergies, chemical substances, and trauma. ILG significantly reduces histopathological damage and increases the levels of inflammatory cell exudation, protein leakage and proinflammatory mediators in carrageenan-induced pleurisy by inhibiting the NLRP3/NF- $\mathrm{kB}$ pathway and high levels of iNOS and COX-2. ${ }^{68}$ ILG strongly inhibits NLRP3 inflammasome activation in macrophages and reduces HFD-induced obesity, lipid homeostasis, insulin resistance, and the accumulation of inflammatory cells and adipose tissue inflammation. ${ }^{69}$ Moreover, ILG treatment inhibits HFD-induced IL-1 $\beta$ and caspase-1 production in epididymal white adipose tissue culture. ${ }^{69}$

\section{Isoliquiritin}

Depression is a common and debilitating mental illness. It is characterized by poor mood, loss of pleasure, and avoidance of social interactions, all of which cause a major social and economic burden. ${ }^{70}$ Although a variety of antidepressant drugs can be used for the treatment of depression, most have a low cure rate, a wide range of side effects and poor treatment compliance. ${ }^{71}$ Therefore, there is an urgent need for new therapies with high curative effects and few adverse reactions. Current evidence indicates that the development of depression is related to pyroptosis mediated by the activation of NLRP3 inflammasome. ${ }^{72-74}$ Isoliquiritin (Figure 2F) protects against LPS and ATP elicited NLRP3 inflammasome activation in primary microglia. ${ }^{75}$ In vivo data show that isoliquiritin administration effectively ameliorates LPS or chronic social defeat stress (CSDS)-induced depressive symptoms by suppressing NLRP3-mediated pyroptosis via miRNA-27a/spleen tyrosine kinase $(\mathrm{SYK}) / \mathrm{NF}-\mathrm{kB}$ axis, ${ }^{75}$ and this provides a new treatment strategy for the treatment of depression.

\section{Glycyrrhizin (GL)}

Glycyrrhizin (Figure 2G) (also called glycyrrhizic acid) is a triterpenoid compound extracted from Glycyrrhiza. GLrelated derivatives are mainly used as sweeteners in the food industry. As a medicine, GL preparation is a powerful liver cell membrane protector that has the effects of antiinflammatory, immune regulation, and hepatocyte protection. ${ }^{76}$ It has been used clinically for many years as an effective drug for chronic hepatitis and has achieved good curative results. ${ }^{77,78}$

Metabolic disease is caused by disorders of amino acid, glucose and lipid metabolism in the body, and chronic inflammation is one of its main characteristics. Studies have shown that GL has significant therapeutic effects on metabolic diseases because of its ability to regulate NLRP3 inflammasome activation. Non-alcoholic steatohepatitis (NASH) is a progressive stage of non-alcoholic fatty liver disease (NAFLD) that may lead to liver cirrhosis and liver cancer. ${ }^{79,80}$ NASH seriously threatens the health of patients, and there is currently a lack of effective treatment options. In recent years, studies have shown that 
NLRP3 inflammasome plays an important biological role in the occurrence and development of NASH. ${ }^{81-83} \mathrm{GL}$ preparations are currently one of the first-line drugs used for anti-inflammatory and hepatoprotective treatments of liver diseases. GL could inhibit deoxycholic acid-induced NLRP3 inflammasome-associated inflammation in macrophage cells. ${ }^{84}$ Importantly, an in vivo experiment shows that GL administration significantly attenuates MCD dietinduced hepatic steatosis, inflammation, and fibrosis and inhibited the activation of NLRP3 inflammasome. Moreover, both intraperitoneal injection of GA and oral administration of GL significantly reduce MCD-induced liver injury, ${ }^{84}$ suggesting that GL may attenuate NASH via its active metabolite GA. Atherosclerosis is the pathological basis of many vascular diseases, such as aneurysms, atherosclerotic obliterans and carotid artery disease. ${ }^{85}$ Lipid metabolism disorder is the pathological basis of atherosclerosis. Inhibiting the atherosclerotic process is beneficial for controlling the development of the abovementioned vascular diseases. GL significantly attenuates LPS/high-fat diet-induced atherosclerosis and NLRP3 inflammasome-dependent high-mobility group Box 1 (HMGB1) secretion in male ApoE $^{-/-}$mice. $^{86}$

In addition, GL has been shown to be effective in a variety of acute inflammatory injury models. Streptococcus aureus (S. aureus) infection facilitates proinflammatory cytokines production and induces damage to multiple organs, including ALI. ${ }^{87} \mathrm{GL}$ treatment reduces serum and lung tissue IL-6, TNF- $\alpha$, IL- 8 , IL- $1 \beta$ and HMGB1 levels, as well as lung tissue neutrophil and macrophage infiltration in $S$. aureus-induced ALI by inhibiting $\mathrm{NF}-\kappa \mathrm{B}, \mathrm{p} 38 /$ extracellular signal-related protein kinases (ERK1/2) pathways, and NLRP3 inflammasome dependent pyroptosis. ${ }^{88}$ In a corneal injury mouse model, it has shown that GL treatment attenuates the expression of IL-1 $\beta$ by directly inhibiting extracellular HMGB1 func-

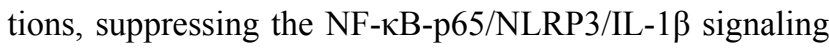
pathway, resulting in the cornea regaining transparency and integrity ${ }^{89}$ (Figure 3). Acute glaucoma is a cause of irreversible blindness that seriously threatens vision and is characterized by a sudden and significant increase in intraocular pressure followed by the death of retinal ganglion cells. ${ }^{90,91}$ HMGB1 is increased in ischemic retinal tissue during acute glaucoma, and the HMGB1 inhibitor, $\mathrm{GL}$, reduces the severity of the disease via regulating the activation of NLRP3 and caspase-8 inflammasomes. ${ }^{92}$ These results provide new insights toward understanding the role of the innate immune response in the pathogenesis of acute glaucoma and provide research strategies for new therapeutic targets for acute glaucoma. Traumatic spinal cord injury can lead to a large amount of nerve cell necrosis and severe functional-behavioral defects in the injured area. ${ }^{93}$ In addition to the primary injury, the subsequent inflammatory process also contributes to secondary injury. ${ }^{94}$ Functional recovery is promoted by GL treatment in rat model subject to traumatic spinal cord injury. The GL treatment results in recovery accompanied by decreased expression of NLRP3 inflammasome components, such as ASC, NLRP3, and cleaved caspase-1, as well as IL-1 $\beta$ and IL-18. ${ }^{95}$

\section{Glycyrrhetinic Acid (GA)}

GA (Figure 2H), a triterpene saponin extracted from Glycyrrhiza plants, reduces LPS-induced ALI pathological damage, macrophage infiltration and pulmonary edema, and inhibits NLRP3 inflammasome and IL-1 $\beta$ secretion mediated by the ROS-PI3K/AKT pathway. ${ }^{96}$ This suggests that it may serve as a potent NLRP3 inflammasome inhibitor with great promise toward the attenuation of ALIrelated inflammation and pathological status. Parkinson's disease (PD) is one of the most common neurodegenerative diseases. It has clinical manifestations including resting tremor, rigidity, bradykinesia, and postural instability, and is characterized by the loss of dopaminergic neurons in the substantia nigra region and the presence of Lewy bodies containing $\alpha$-synuclein. ${ }^{97,98}$ A large amount of evidence confirms the relationship between Parkinson's and NLRP3 inflammasome. ${ }^{99-101} \mathrm{GA}$, Glycyrrhiza inflata, and Shaoyao Gancao decoction (a formulated Chinese medicine) all exhibit anti-inflammatory effects that ameliorate neurotoxicity induced by $\alpha$-synuclein in BV-2 and A53T SNCA-GFP SH-SY5Y cells by suppressing NLRP1/ NLRP3 inflammasome, IL-1 $\beta$-mediated I $\mathrm{B} \alpha / \mathrm{P} 65$, JNK/ JUN, P38/STAT1, and IL-6-mediated JAK2/STAT3 pathways; ${ }^{102}$ This indicates that related components and preparations of licorice may be used as drugs for the treatment of neurodegenerative diseases such as PD.

Carbenoxolone (Figure 2I), a synthetic derivative of GA, is frequently used in the treatment of gastric ulcers, psoriasis, and wound healing. The NLRP3 inflammasome is a culprit behind the chronic inflammation that accompanies insulin resistance in obese mice. ${ }^{103-105}$ Carbenoxolone ameliorates insulin resistance in the liver and skeletal muscle of high-fat diet-induced obese mice by inhibiting I $\mathrm{I} B-\alpha / \mathrm{NF}-\kappa \mathrm{B}$ pathway and NLRP3 
inflammasome activation, ${ }^{106}$ and it deserves further study for the treatment of obesity related diseases.

\section{Licorice Extract}

Glycyrrhiza plants, especially flavonoids, induce strong anti-inflammatory and immunomodulatory activities. The major flavonoid components in Glycyrrhiza uralensis are liquiritin apioside, liquiritin, naringin, liquiritigenin, quercetin, Lico A and glabridin, as measured by high-performance liquid chromatography analysis. ${ }^{107}$ The upregulated mRNA and protein levels of TNF- $\alpha$, IL-1 $\beta$, and IL- 6 , are significantly decreased by all of the flavonoids from Glycyrrhiza uralensis in the colonic tissue of irinotecan-induced colitis mice, and the flavonoids also inhibit the activation of NLRP3 inflammasome triggered by irinotecan. ${ }^{107}$ Huangqi decoction (Astragali Radix and Glycyrrhizae Radix et Rhizoma), a classic Chinese herbal formula, ameliorates 3,5diethoxycarbonyl-1,4-dihydrocollidine-induced cholestatic liver injury, and alleviates the increased hepatic expression of pro-inflammatory factors and NLRP3 inflammasome activation. ${ }^{108}$

\section{Discussion}

Since NLRP3 inflammasome is involved in the occurrence of a variety of inflammatory diseases, NLRP3 inflammasome may become a potential drug target for these diseases. ${ }^{27,109,110}$ Therefore, exploring the pathogenesis of these diseases from the perspective of inflammation and NLRP3 inflammasome activation, and then developing related drugs may bring new hope for treatment. At present, therapeutic strategies targeting NLRP3 inflammasome mainly block the interaction between IL- $1 \beta$ and its receptor using antibodies or antagonists that inhibit the inflammatory response. However, due to the pro-inflammatory cytokines produced by the activation of NLRP3 inflammasome, there are other pro-inflammatory factors in addition to IL-1 $\beta$, such as the presence of IL-18. Therefore, the treatment strategy of blocking IL-1 $\beta$ requires further investigation, especially in diseases of complex etiology that may not respond as well to therapy. For this reason, the development of drugs targeting NLRP3 inflammasome itself and its related signaling pathways will become a rapidly growing area of research. However, to date, the understanding of NLRP3 inflammasome activation and its regulatory mechanisms is still very limited, and there is a lack of clinical drugs targeting NLRP3 inflammasome. In recent years, good progress has been made in research on intervention strategies targeting NLRP3 inflammasomes. Recent research in our lab has found that many active ingredients in TCMs could serve as candidate therapeutic drugs for NLRP3-driven diseases by suppressing NLRP3 inflammasome activation. Cardamonin (from Alpinia katsumadai) could reduce lethal LPS-induced mortality and attenuate IL-1 $\beta$ production in the septic-shock mouse model by inhibiting the activation of NLRP3 inflammasome. ${ }^{111}$ In addition, the active components carnosol and cryptotanshinone reduce caspase- 1 activation and IL-1 $\beta$ secretion in MCD-induced NASH mouse model by regulating NLRP3 inflammasome activation. ${ }^{12,113}$ Therefore, the development of small molecule compounds targeting NLRP3 inflammasome may provide new treatment strategies for complex diseases.

Glycyrrhiza contains a variety of active ingredients and is one of the most commonly used Chinese medicines. A common Chinese idiom is nine out of ten prescriptions contain Glycyrrhiza. Ancient documentation on Chinese herbal classics record that Glycyrrhiza could "harmonize all kinds of drugs and cure all kinds of toxins", but it is unclear how to regulate these activities. This review details the extensive anti-inflammatory effects of various components in Glycyrrhiza via inhibition of NLRP3 inflammasome activation. Our previous studies also show that the drugs carbamazepine, isoniazid and nevirapine, as well as Chinese medicines such as Epimedium folium and Psoraleae frucitus, can promote the activation of NLRP3 inflammasome and lead to liver injury. ${ }^{114-116}$ Therefore, we believe that one of the scientific connotations of the description of Glycyrrhiza's ability to "harmonize all kinds of drugs and cure all kinds of toxins" is the broad spectrum of antagonistic effects: abnormal activation of NLRP3 inflammasome signaling pathway is involved in the occurrence and development of various diseases, and active ingredients in Glycyrrhiza slow the process and reduce the development of related diseases by inhibiting NLRP3 inflammasome, and thus are capable of "mediating various drugs and eliminating all toxins".

The overall concept of TCMs and the characteristics of low adverse reactions have received more attention. The current application of Glycyrrhiza's anti-inflammatory effects has demonstrated the unique advantages of reducing side effects, improving prognosis during disease treatment, and improving the survival rate of patients. This review summarizes current research on active ingredients 
in Glycyrrhiza, such as Lico A, echinatin, GL, and ILG, that inhibit the activity of NLRP3 inflammasome in the treatment of ALI, DN, NASH, and other NLRP3-driven inflammatory diseases (Table 1). However, the pharmacological mechanism and clinical application of Glycyrrhiza via suppression NLRP3 inflammasome activation have not been systematically and thoroughly studied, and the specific action links are not yet detailed enough, especially at the cellular and molecular levels. As the chemical composition of Glycyrrhiza is complex and contains a variety of anti-inflammatory components, it is not clear whether these components have a synergistic or an antagonistic effect on inflammatory responses. Therefore, in-depth research in this area still needs to be conducted. Since Glycyrrhiza is one of the most frequently used TCMs, clarifying the molecular biological mechanisms and signal transduction pathways explaining how Glycyrrhiza inhibits NLRP3 inflammasome will better characterize its antiinflammatory effect, and provide the basis for developing new indications and for guiding clinical use of Glycyrrhiza. This has important theoretical and practical significance.

Table I NLRP3 Inflammasome Inhibitors as Well as Their Effects in Glycyrrhiza for NLRP3-Driven Diseases

\begin{tabular}{|c|c|c|c|}
\hline Agent & Cell/Animal Model & Effect and Function & Ref. \\
\hline \multirow[t]{5}{*}{ Lico A } & $\begin{array}{l}\text { LPS/GalN-induced acute liver injury } \\
\text { mouse model }\end{array}$ & $\begin{array}{l}\text { Acute liver injury } \downarrow \text {, TNF- } \alpha \downarrow, \text { IL-6 } \downarrow \downarrow \text {, IL-I } \beta \downarrow \text {, Txnip-NLRP3 inflammasome } \\
\text { signaling pathway } \downarrow\end{array}$ & [32] \\
\hline & Primary mouse chondrocytes & IL-I $\beta \downarrow$, IL-I8 $\downarrow$, pyroptosis $\downarrow$, Nrf2/HO-I signal pathway $\uparrow$ & [26] \\
\hline & Air pouch mouse model & IL-I $\beta \downarrow$, IL-I8\ & [26] \\
\hline & $\begin{array}{l}\text { Bone marrow-derived primary } \\
\text { macrophages (BMDMs) and human SZ95 } \\
\text { sebocytes }\end{array}$ & $\begin{array}{l}\text { Caspase-I }(p \mid 0) \downarrow \text {, IL-I } \mid \text {, mitochondrial reactive oxygen species } \\
\text { production } \downarrow\end{array}$ & [36] \\
\hline & $\begin{array}{l}\text { Intradermal infection of } P \text {. acnes mouse } \\
\text { mode }\end{array}$ & Skin inflammation $\downarrow$, caspase-I activity $\downarrow$, IL-I $\beta \downarrow$ & [36] \\
\hline \multirow[t]{4}{*}{ Lico B } & $\begin{array}{l}\text { BMDMs, THP-I cells, and human } \\
\text { PBMCs }\end{array}$ & 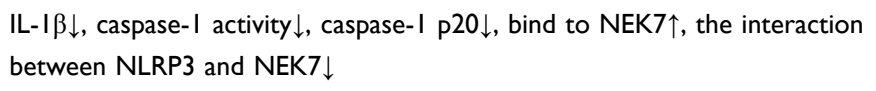 & [38] \\
\hline & LPS-induced septic shock & $\begin{array}{l}\text { Mouse survival } \uparrow, I L-I \beta \downarrow \text {, the number of peritoneal exudative cells } \downarrow \text {, } \\
\text { peritoneal macrophages } \downarrow\end{array}$ & [38] \\
\hline & MSU-induced mouse peritonitis & IL-I $\beta \downarrow$, the number of peritoneal exudates $\downarrow$, neutrophils $\downarrow$ & [38] \\
\hline & MCD diet-induced NASH mouse model & $\begin{array}{l}\text { Liver steatosis } \downarrow \text {, balloon dilatation } \downarrow \text {, fibrosis } \downarrow \text {, the protein level of active } \\
\text { caspase-I in liver tissue } \downarrow \text {, the pro-fibrotic marker alpha smooth muscle actin ( } \alpha \text { - } \\
\text { SMA) } \downarrow \text {, mRNA expression of colla } \downarrow \downarrow \text {, TNF- } \alpha \downarrow \text {, IL-I } \beta \downarrow \text { and IL-I8 } \downarrow \text {, serum IL- } \\
\text { I8 } \downarrow\end{array}$ & [38] \\
\hline \multirow[t]{2}{*}{ Liquiritigenin } & $\begin{array}{l}\text { Potassium oxonate-induced } \\
\text { hyperuricemic rat model }\end{array}$ & $\begin{array}{l}\text { The level of uric acid in serum and urine } \downarrow \text {, IL-I } \beta \downarrow \text {, IL- } 6 \downarrow \text {, TNF- } \alpha \downarrow \text {, renal } \\
\text { AQP4/NF- } \mathrm{B} B / \mathrm{k} B \alpha \text { signaling and NLRP3 inflammasome activation } \downarrow\end{array}$ & {$[44]$} \\
\hline & $\begin{array}{l}\text { The rat glomerular mesangial cell line } \\
\text { HBZY-I }\end{array}$ & $\begin{array}{l}\text { High glucose-induced extracellular matrix accumulation } \downarrow \text {, oxidative stress } \downarrow \text {, } \\
\text { IL- } 6 \text { and IL-I } \beta \text { production } \downarrow, \text { NF-KB and NLRP3 inflammasome pathways } \downarrow\end{array}$ & [47] \\
\hline \multirow[t]{4}{*}{ Echinatin } & Mouse BMDMs and human PBMCs & $\begin{array}{l}\text { Bind to heat-shock protein } 90 \uparrow \text {, ATPase activity } \downarrow \text {, the association between } \\
\text { the cochaperone SGTI and HSP90-NLRP } 3 \downarrow\end{array}$ & {$[50]$} \\
\hline & LPS-induced septic shock mouse model & IL-I $\beta \downarrow$, TNF- $\alpha$ production $\downarrow$, mouse survival $\uparrow$ & {$[50]$} \\
\hline & $\begin{array}{l}\text { Dextran sodium sulfate-induced colitis } \\
\text { mouse model }\end{array}$ & $\begin{array}{l}\text { Colonic inflammation } \downarrow \text {, mucosal barrier and inflammatory cell infiltration } \downarrow \text {, } \\
\text { caspase-I activation } \downarrow \text {, IL-I } \beta \text { production } \downarrow\end{array}$ & {$[50]$} \\
\hline & MCD diet-induced NASH mouse model & $\begin{array}{l}\text { Morphological changes } \downarrow \text {, hepatic steatosis } \downarrow \text {, ballooning } \downarrow \text {, fibrosis } \downarrow \text {, caspase-I } \\
\text { activation } \downarrow \text {, mRNA expression of proinflammatory genes IL-I } \beta \text { and TNF- } \alpha \downarrow\end{array}$ & {$[50]$} \\
\hline
\end{tabular}

(Continued) 
Table I (Continued).

\begin{tabular}{|c|c|c|c|}
\hline Agent & Cell/Animal Model & Effect and Function & Ref. \\
\hline \multirow[t]{9}{*}{ ILG } & Kainic acid-induced seizures rat model & TNF- $\alpha \downarrow$, IL-I $\beta \downarrow$, IL-I8 $\downarrow$, NLRP3 $\downarrow$, Caspase-I $\downarrow$ & [54] \\
\hline & $\begin{array}{l}\text { Carrageenan-induced pleurisy mouse } \\
\text { model }\end{array}$ & TNF- $\alpha \downarrow$, IL-I $\mid \beta \downarrow$, IL- $6 \downarrow$, the NLRP3/NF-kB pathway $\downarrow$, iNOS $\downarrow$, COX-2 $\downarrow$ & [68] \\
\hline & $\begin{array}{l}\text { The mouse periodontal ligament } \\
\text { fibroblasts }\end{array}$ & $\begin{array}{l}\text { Chronic periodontitis } \downarrow \text {, caspase-I activation } \downarrow \text {, IL-I } \downarrow \downarrow \text {, HMGBI } \downarrow \text {, ROS/ } \\
\text { TXNIP/NIrp3 inflammasome pathway } \downarrow\end{array}$ & [67] \\
\hline & $\begin{array}{l}\text { Collagenase IV-induced intracerebral } \\
\text { hemorrhage rat model }\end{array}$ & $\begin{array}{l}\text { Neurological deficits } \downarrow \text {, histological damages } \downarrow \text {, blood-brain barrier } \\
\text { disruption } \downarrow \text {, brain edema } \downarrow \text {, neuronal degeneration } \downarrow \text {, the NF- } \mathrm{KB} \text { and NLRP3 } \\
\text { inflammasome pathways } \downarrow \text {, Nrf2-mediated antioxidant system } \uparrow\end{array}$ & {$[58]$} \\
\hline & LPS-induced ALI mouse model & $\begin{array}{l}\text { Recruitment of inflammatory cells } \downarrow \text {, COX-2 } \downarrow \text {, iNOS } \downarrow \text {, TNF- } \alpha \downarrow \text {, IL-I } \beta \downarrow \text {, IL- } 6 \downarrow \text {, } \\
\text { the AMPK/Nrf2 signaling and its downstream antioxidant enzymes } \uparrow \text {, the } \\
\text { NLRP3 inflammasome and NF- } \mathrm{kB} \text { pathways } \downarrow\end{array}$ & {$[62]$} \\
\hline & $\begin{array}{l}\text { In vitro model of ischemia in } \\
\text { organotypic slice cultures }\end{array}$ & Ischemic neuronal death $\downarrow$, NLRP3 inflammasome activation $\downarrow$ & {$[55]$} \\
\hline & $\begin{array}{l}\text { Indomethacin-induced small intestinal } \\
\text { damage mouse model }\end{array}$ & Small intestinal damage $\downarrow$, cleaved caspase-I $\downarrow$, mature IL-I $\beta$ protein levels $\downarrow$ & [63] \\
\hline & $\begin{array}{l}\text { Ex vivo culture of epididymal white } \\
\text { adipose tissue }\end{array}$ & Adipose tissue inflammation $\downarrow$, IL-I $\beta \downarrow$, caspase-I production $\downarrow$ & [69] \\
\hline & $\begin{array}{l}\text { HFD-induced adipose tissue } \\
\text { inflammation }\end{array}$ & The accumulation of inflammatory cells $\downarrow$, adipose tissue inflammation $\downarrow$ & [69] \\
\hline \multirow[t]{2}{*}{ Isoliquiritin } & $\begin{array}{l}\text { LPS or CSDS-induced depression } \\
\text { mouse model }\end{array}$ & $\begin{array}{l}\text { The protein levels of SYK } \downarrow \text {, p-NF-KB } \downarrow \text {, NLRP } 3 \downarrow \text {, caspase-I } \downarrow \text {, IL-I } \mid \text {, } \\
\text { GSDMD-N } \downarrow \text {; the concentration of IL-I } \beta \downarrow \text {, IL- } 6 \downarrow \text {, TNF- } \alpha \downarrow\end{array}$ & {$[75]$} \\
\hline & Mouse primary microglia & Protein levels of $\mathrm{p}-\mathrm{NF}-\mathrm{kB} \downarrow, \mathrm{NLRP} 3 \downarrow$; cleaved caspase-I $\downarrow, \mathrm{IL}-\mathrm{I} \beta \downarrow, \mathrm{GSDMD}-\mathrm{N} \downarrow$ & {$[75]$} \\
\hline \multirow[t]{7}{*}{ GL } & MCD diet-induced NASH mouse model & $\begin{array}{l}\text { NASH-induced liver injury } \downarrow \text {, liver fibrosis } \downarrow \text {, hepatic lipid accumulation } \downarrow \text {, bile } \\
\text { acid accumulation } \downarrow \text {, NLRP3 inflammasome activation and Meta- } \\
\text { inflammation } \downarrow\end{array}$ & [84] \\
\hline & Raw 264.7 macrophage cells & Deoxycholic acid-induced NLRP3 inflammasome-associated inflammation $\downarrow$ & {$[84]$} \\
\hline & $\begin{array}{l}\text { LPS/HFD-induced atherosclerosis in } \\
\text { ApoE }^{-1-} \text { mice }\end{array}$ & Atherosclerosis $\downarrow$, serum HMGBI levels $\downarrow$, NLRP3 inflammasome activation $\downarrow$ & [86] \\
\hline & $\begin{array}{l}\text { Streptococcus aureus-induced ALI } \\
\text { mouse model }\end{array}$ & $\begin{array}{l}\text { Serum and lung tissue IL- } 6 \downarrow \text {, TNF- } \alpha \downarrow \text {, IL- } 8 \downarrow \text {, IL-I } \beta \downarrow \text {, HMGBI } \downarrow \text {, lung tissue } \\
\text { neutrophil and macrophage infiltration } \downarrow, \text { NF- } \mathrm{K} B \downarrow, \text { P38/ERK pathways } \downarrow \text {, } \\
\text { Pyroptosis } \downarrow\end{array}$ & [88] \\
\hline & A corneal injury mouse model & $\begin{array}{l}\text { The expression of IL-I } \beta \downarrow \text {, extracellular HMGBI functions } \downarrow \text {, the NF- } \mathrm{KB}-\mathrm{p} 65 / \\
\text { NLRP3/IL-I } \beta \text { signaling pathway } \downarrow\end{array}$ & {$[89]$} \\
\hline & An acute glaucoma mouse model & $\begin{array}{l}\text { The severity of the disease } \downarrow \text {, the activation of NLRP3 and caspase-8 } \\
\text { inflammasomes } \downarrow\end{array}$ & {$[92]$} \\
\hline & Traumatic spinal cord injury rat model & $\begin{array}{l}\text { Expression of NLRP3 inflammasome components } \downarrow \text {, ASC } \downarrow \text {, NLRP3 } \downarrow \text {, cleaved } \\
\text { caspase- I } \downarrow \text {, IL-I } \beta \downarrow, \text { IL- I8 } \downarrow\end{array}$ & {$[95]$} \\
\hline \multirow[t]{2}{*}{ GA } & Mouse BV-2 microglial cells & Nitric oxide $\downarrow$, IL-I $\beta$ maturation $\downarrow$ & {$[102$} \\
\hline & LPS-induced ALI mouse model & ALI $\downarrow$, the activation of NLRP3 inflammasome $\downarrow$, ROS-PI3K/AKT pathway $\downarrow$ & [96] \\
\hline
\end{tabular}

(Continued) 
Table I (Continued).

\begin{tabular}{|l|l|l|l|}
\hline Agent & \multicolumn{1}{|c|}{ Cell/Animal Model } & \multicolumn{1}{c|}{ Effect and Function } & Ref. \\
\hline Carbenoxolone & HFD-induced obese mouse model & Insulin sensitivity $\downarrow$, the IKB- $\alpha /$ NF-kB pathway and NLRP3 inflammasome $\downarrow$, & {$[106]$} \\
\hline Licorice extract & Irinotecan-induced colitis mouse model & The mRNA and protein levels of TNF- $\alpha \downarrow$, IL-I $\beta \downarrow$, and IL-6 $\downarrow$ & {$[107]$} \\
\hline
\end{tabular}

Notes: $\downarrow$, inhibition; $\uparrow$, promotion.

\section{Acknowledgments}

This work has been supported by National Natural Science Foundation of China (81874368, 81630100, 81721002), Innovation Team and Talents Cultivation Program of National Administration of Traditional Chinese Medicine. (No: ZYYCXTD-C-202005), National Science \& Technology Major Project "Key New Drug Creation and Manufacturing Program" (2017ZX09301022 and 2018ZX09101002-001-002).

\section{Disclosure}

The authors report no conflicts of interest in this work.

\section{References}

1. Zindel J, Kubes P. DAMPs, PAMPs, and LAMPs in immunity and sterile inflammation. Annu Rev Pathol. 2020;15:493-518. doi:10.1146/annurev-pathmechdis-012419-032847

2. Sorriento D, Iaccarino G. Inflammation and cardiovascular diseases: the most recent findings. Int J Mol Sci. 2019;20(16):3879.

3. Abdolmaleki F, Kovanen PT, Mardani R, Gheibi-Hayat SM, Bo S, Sahebkar A. Resolvins: emerging players in autoimmune and inflammatory diseases. Clin Rev Allergy Immunol. 2020;58 (1):82-91. doi:10.1007/s12016-019-08754-9

4. Eming SA, Krieg T, Davidson JM. Inflammation in wound repair: molecular and cellular mechanisms. J Invest Dermatol. 2007;127 (3):514-525. doi:10.1038/sj.jid.5700701

5. Dona I, Salas M, Perkins JR, et al. Hypersensitivity reactions to non-steroidal anti-inflammatory drugs. Curr Pharm Des. 2016;22 (45):6784-6802. doi:10.2174/1381612822666160928142814

6. Freeman TL, Swartz TH. Targeting the NLRP3 inflammasome in severe COVID-19. Front Immunol. 2020;11:1518. doi:10.3389/ fimmu.2020.01518

7. Liu D, Zeng X, Li X, et al. Advances in the molecular mechanisms of NLRP3 inflammasome activators and inactivators. Biochem Pharmacol. 2020;175:113863. doi:10.1016/j.bcp.2020. 113863

8. Yang Q, Liu R, Yu Q, Bi Y, Liu G. Metabolic regulation of inflammasomes in inflammation. Immunology. 2019;157(2):95109.

9. Fusco R, Siracusa R, Genovese Tet al. Focus on the role of NLRP3 inflammasome in diseases. Int $J$ Mol Sci. 2020;21 (12):4223.

10. Wang L, Hauenstein AV. The NLRP3 inflammasome: mechanism of action, role in disease and therapies. Mol Aspects Med. 2020;76:100889. doi:10.1016/j.mam.2020.100889

11. Zhen Y, Zhang H. NLRP3 inflammasome and inflammatory bowel disease. Front Immunol. 2019;10:276. doi:10.3389/ fimmu.2019.00276
12. El-Saber Batiha G, Magdy beshbishy A, El-Mleeh A, AbdelDaim MM, Prasad Devkota H. Traditional uses, bioactive chemical constituents, and pharmacological and toxicological activities of Glycyrrhiza glabra L. (Fabaceae). Phytother Res. 2020;10 (3):352.

13. Pastorino G, Cornara L, Soares S, Rodrigues F, Oliveira MBPP. Liquorice (Glycyrrhiza glabra): a phytochemical and pharmacological review. Phytother Res. 2018;32(12):2323-2339. doi:10. 1002/ptr.6178

14. Wang ZF, Liu J, Yang YA, Zhu HL. A review: the anti-inflammatory, anticancer and antibacterial properties of four kinds of licorice flavonoids isolated from licorice. Curr Med Chem. 2020;27(12):1997-2011. doi:10.2174/0929867325666181001104 550

15. Yang R, Yuan BC, Ma YS, Zhou S, Liu Y. The anti-inflammatory activity of licorice, a widely used Chinese herb. Pharm Biol. 2017;55(1):5-18. doi:10.1080/13880209.2016.1225775

16. Broz P, Dixit VM. Inflammasomes: mechanism of assembly, regulation and signalling. Nat Rev Immunol. 2016;16(7):407420. doi:10.1038/nri.2016.58

17. Strowig T, Henao-Mejia J, Elinav E, Flavell R. Inflammasomes in health and disease. Nature. 2012;481(7381):278-286. doi:10.10 38/nature10759

18. Lamkanfi M, Dixit VM. Mechanisms and functions of inflammasomes. Cell. 2014;157(5):1013-1022. doi:10.1016/j.cell.2014. 04.007

19. He Y, Hara H, Núñez G. Mechanism and regulation of NLRP3 inflammasome activation. Trends Biochem Sci. 2016;41 (12):1012-1021. doi:10.1016/j.tibs.2016.09.002

20. Jo EK, Kim JK, Shin DM, Sasakawa C. Molecular mechanisms regulating NLRP3 inflammasome activation. Nat Rev Immunol. 2016;13(2):148-159.

21. Swanson KV, Deng M, Ting JP-Y. The NLRP3 inflammasome: molecular activation and regulation to therapeutics. Nat Rev Immunol. 2019;19(8):477-489. doi:10.1038/s41577-019-0165-0

22. Lagarto JL, Nickdel MB, Kelly DJ, Price A, Nanchahal J. Autofluorescence lifetime reports cartilage damage in osteoarthritis. Sci Rep. 2020;10(1):2154. doi:10.1038/s41598-020-59219-5

23. Xia B, Di C, Zhang J, Hu S, Jin H, Tong P. Osteoarthritis pathogenesis: a review of molecular mechanisms. Calcif Tissue Int. 2014;95(6):495-505. doi:10.1007/s00223-014-9917-9

24. An S, Hu H, Li Y, Hu Y. Pyroptosis plays a role in osteoarthritis. Aging Dis. 2020;11(5):1146-1157. doi:10.14336/AD.2019.1127

25. McAllister MJ, Chemaly M, Eakin AJ, Gibson DS, McGilligan VE. NLRP3 as a potentially novel biomarker for the management of osteoarthritis. Osteoarthritis Cartilage. 2018;26(5):612-619. doi:10.1016/j.joca.2018.02.901

26. Yan Z, Qi W, Zhan J, et al. Activating Nrf2 signalling alleviates osteoarthritis development by inhibiting inflammasome activation. J Cell Mol Med. 2020;24(22):13046-13057. doi:10.1111/ jcmm. 15905

27. Abderrazak A, Syrovets T, Couchie D, et al. NLRP3 inflammasome: from a danger signal sensor to a regulatory node of oxidative stress and inflammatory diseases. Redox Biol. 2015;4:296307. doi:10.1016/j.redox.2015.01.008 
28. Zhou R, Tardivel A, Thorens B, Choi I, Tschopp J. Thioredoxininteracting protein links oxidative stress to inflammasome activation. Nat Immunol. 2010;11(2):136-140. doi:10.1038/ni.1831

29. Liu X, Wang T, Liu X, et al. Biochanin A protects lipopolysaccharide/D-galactosamine-induced acute liver injury in mice by activating the Nrf2 pathway and inhibiting NLRP3 inflammasome activation. Int Immunopharmacol. 2016;38:324-331. doi:10. 1016/j.intimp.2016.06.009

30. Pan CW, Pan ZZ, Hu JJ, et al. Mangiferin alleviates lipopolysaccharide and D-galactosamine-induced acute liver injury by activating the Nrf2 pathway and inhibiting NLRP3 inflammasome activation. Eur J Pharmacol. 2016;770:85-91. doi:10.1016/j. ejphar.2015.12.006

31. Wang F, Gong S, Wang T, et al. Soyasaponin II protects against acute liver failure through diminishing YB-1 phosphorylation and Nlrp3-inflammasome priming in mice. Theranostics. 2020;10 (6):2714-2726. doi:10.7150/thno.40128

32. Lv H, Yang H, Wang Z, et al. Nrf2 signaling and autophagy are complementary in protecting lipopolysaccharide/d-galactosamineinduced acute liver injury by licochalcone A. Cell Death Dis. 2019;10(4):313. doi:10.1038/s41419-019-1543-z

33. Li ZJ, Choi DK, Sohn KC, et al. Propionibacterium acnes activates the NLRP3 inflammasome in human sebocytes. J Invest Dermatol. 2014;134(11):2747-2756. doi:10.1038/jid.2014.221

34. Contassot E, French LE. New insights into acne pathogenesis: propionibacterium acnes activates the inflammasome. $J$ Invest Dermatol. 2014;134(2):310-313. doi:10.1038/jid.2013.505

35. Kistowska M, Gehrke S, Jankovic D, et al. IL-1 $\beta$ drives inflammatory responses to propionibacterium acnes in vitro and in vivo. $J$ Invest Dermatol. 2014;134(3):677-685. doi:10.1038/jid.2013.438

36. Yang G, Lee HE, Yeon SH, et al. Licochalcone A attenuates acne symptoms mediated by suppression of NLRP3 inflammasome. Phytother Res. 2018;32(12):2551-2559. doi:10.1002/ptr.6195

37. Wang J, Liao AM, Thakur K, Zhang JG, Huang J-H, Wei Z-J. Licochalcone B extracted from Glycyrrhiza uralensis Fisch induces apoptotic effects in human hepatoma cell HepG2. Journal of Agricultural and Food Chemistry. 2019;67(12):33413353. doi:10.1021/acs.jafc.9b00324

38. Li Q, Feng H, Wang H, et al. Licochalcone B specifically inhibits the NLRP3 inflammasome by disrupting NEK7-NLRP3 interaction. EMBO Rep. 2021:e53499. doi:10.15252/embr.202153499

39. Dalbeth N, Choi HK, Joosten LAB, et al. Gout. Nat Rev Dis Primers. 2019;5(1):69. doi:10.1038/s41572-019-0115-y

40. Dehlin M, Jacobsson L, Roddy E. Global epidemiology of gout: prevalence, incidence, treatment patterns and risk factors. Nat Rev Rheumatol. 2020;16(7):380-390. doi:10.1038/s41584-020-0441-1

41. Cui D, Liu S, Tang M, et al. Phloretin ameliorates hyperuricemiainduced chronic renal dysfunction through inhibiting NLRP3 inflammasome and uric acid reabsorption. Phytomedicine. 2020;66:153111. doi:10.1016/j.phymed.2019.153111

42. Dalbeth N, Merriman TR, Stamp LK. Gout. Lancet. 2016;388 (10055):2039-2052. doi:10.1016/S0140-6736(16)00346-9

43. Isaka Y, Takabatake $\mathrm{Y}$, Takahashi A, Saitoh T, Yoshimori T. Hyperuricemia-induced inflammasome and kidney diseases. Nephrol Dial Transplant. 2016;31(6):890-896. doi:10.1093/ndt/ gfv024

44. Hongyan L, Suling W, Weina Z, Yajie Z, Jie R. Antihyperuricemic effect of liquiritigenin in potassium oxonateinduced hyperuricemic rats. Biomed Pharmacother. 2016;84: 1930-1936. doi:10.1016/j.biopha.2016.11.009

45. Wada J, Makino H. Inflammation and the pathogenesis of diabetic nephropathy. Clin Sci. 2013;124(3):139-152. doi:10.1042/ CS20120198

46. Choi KM, Yoo HS. Amelioration of hyperglycemia-induced nephropathy by 3,3'-diindolylmethane in diabetic mice. Molecules. 2019;24(24):4474.
47. Zhu X, Shi J, Li H. Liquiritigenin attenuates high glucoseinduced mesangial matrix accumulation, oxidative stress, and inflammation by suppression of the NF- $\mathrm{BB}$ and NLRP3 inflammasome pathways. Biomed Pharmacother. 2018;106:976-982. doi:10.1016/j.biopha.2018.07.045

48. Fu Y, Chen J, Li YJ, Zheng YF, Li P. Antioxidant and antiinflammatory activities of six flavonoids separated from licorice. Food Chem. 2013;141(2):1063-1071. doi:10.1016/j.foodchem.20 13.03 .089

49. Ji S, Li Z, Song W, et al. Bioactive constituents of Glycyrrhiza uralensis (Licorice): discovery of the effective components of a traditional herbal medicine. J Nat Prod. 2016;79(2):281-292. doi:10.1021/acs.jnatprod.5b00877

50. Xu G, Fu S, Zhan X, et al. Echinatin effectively protects against NLRP3 inflammasome-driven diseases by targeting HSP90. JCI Insight. 2021;6(2). doi:10.1172/jci.insight.134601

51. Peng F, Du Q, Peng C, et al. A review: the pharmacology of isoliquiritigenin. Phytother Res. 2015;29(7):969-977. doi:10.10 $02 /$ ptr.5348

52. Wang L, Yang R, Yuan B, Liu Y, Liu C. The antiviral and antimicrobial activities of licorice, a widely-used Chinese herb. Acta Pharm Sin B. 2015;5(4):310-315. doi:10.1016/j.apsb.2015.05.005

53. Zhao TT, Xu YQ, Hu HM, Gong HB, Zhu HL. Isoliquiritigenin (ISL) and its formulations: potential antitumor agents. Curr Med Chem. 2019;26(37):6786-6796. doi:10.2174/0929867325666181112091700

54. Zhu X, Liu J, Huang S, et al. Neuroprotective effects of isoliquiritigenin against cognitive impairment via suppression of synaptic dysfunction, neuronal injury, and neuroinflammation in rats with kainic acid-induced seizures. Int Immunopharmacol. 2019;72: 358-366. doi:10.1016/j.intimp.2019.04.028

55. d'Adesky ND, de Rivero Vaccari JP, Bhattacharya P, et al. Nicotine alters estrogen receptor-beta-regulated inflammasome activity and exacerbates ischemic brain damage in female rats. Int J Mol Sci. 2018;19(5):1330. doi:10.3390/ijms19051330

56. Keep RF, Hua Y, Xi G. Intracerebral haemorrhage: mechanisms of injury and therapeutic targets. Lancet Neurol. 2012;11(8):720731. doi:10.1016/S1474-4422(12)70104-7

57. Adeoye O, Broderick JP. Advances in the management of intracerebral hemorrhage. Nat Rev Neurol. 2010;6(11):593-601. doi:10.1038/nrneurol.2010.146

58. Zeng J, Chen Y, Ding R. Isoliquiritigenin alleviates early brain injury after experimental intracerebral hemorrhage via suppressing ROS- and/or NF- $\mathrm{BB}-$ mediated NLRP3 inflammasome activation by promoting Nrf2 antioxidant pathway. $J$ Neuroinflammat. 2017;14(1):119. doi:10.1186/s12974-017-0895-5

59. Zhang Y, Li X, Grailer JJ, et al. Melatonin alleviates acute lung injury through inhibiting the NLRP3 inflammasome. J Pineal Res. 2016;60(4):405-414. doi:10.1111/jpi.12322

60. Hosseinian N, Cho Y, Lockey RF, Kolliputi N. The role of the NLRP3 inflammasome in pulmonary diseases. Ther Adv Respir Dis. 2015;9(4):188-197. doi:10.1177/1753465815586335

61. Lee S, Suh GY, Ryter SW, Choi AM. Regulation and function of the nucleotide binding domain leucine-rich repeat-containing receptor, pyrin domain-containing-3 inflammasome in lung disease. Am J Respir Cell Mol Biol. 2016;54(2):151-160. doi:10. 1165/rcmb.2015-0231TR

62. Liu Q, Lv H, Wen Z, Ci X, Peng L. Isoliquiritigenin activates nuclear factor erythroid-2 related factor 2 to suppress the NODlike receptor protein 3 inflammasome and inhibits the NF- $\mathrm{BB}$ pathway in macrophages and in acute lung injury. Front Immunol. 2017;8:1518. doi:10.3389/fimmu.2017.01518

63. Nakamura $S$, Watanabe $T$, Tanigawa $T$, et al. Isoliquiritigenin ameliorates indomethacin-induced small intestinal damage by inhibiting NOD-like receptor family, pyrin domain-containing 3 inflammasome activation. Pharmacology. 2018;101(5-6):236245. doi:10.1159/000486599 
64. Persson GR. Periodontal complications with age. Periodontol 2000. 2018;78(1):185-194. doi:10.1111/prd.12227

65. El-Awady AR, Messer RL, Gamal AY, Sharawy MM, Wenger $\mathrm{KH}$, Lapp CA. Periodontal ligament fibroblasts sustain destructive immune modulators of chronic periodontitis. J Periodontol. 2010;81(9):1324-1335. doi:10.1902/jop.2010.100054

66. Scheres N, Laine ML, Sipos PM, et al. Periodontal ligament and gingival fibroblasts from periodontitis patients are more active in interaction with Porphyromonas gingivalis. J Periodontal Res. 2011;46(4):407-416. doi:10.1111/j.1600-0765.2011.01353.x

67. Lian D, Dai L, Xie Z, et al. Periodontal ligament fibroblasts migration injury via ROS/TXNIP/Nlrp3 inflammasome pathway with Porphyromonas gingivalis lipopolysaccharide. Mol Immunol. 2018;103:209-219. doi:10.1016/j.molimm.2018.10.001

68. Gao Y, Lv X, Yang H, Peng L, Ci X. Isoliquiritigenin exerts antioxidative and anti-inflammatory effects via activating the KEAP-1/Nrf2 pathway and inhibiting the NF- $\mathrm{BB}$ and NLRP3 pathways in carrageenan-induced pleurisy. Food Funct. 2020;11 (3):2522-2534. doi:10.1039/C9FO01984G

69. Honda H, Nagai Y, Matsunaga T, et al. Isoliquiritigenin is a potent inhibitor of NLRP3 inflammasome activation and diet-induced adipose tissue inflammation. J Leukoc Biol. 2014;96(6):10871100. doi:10.1189/jlb.3A0114-005RR

70. Alexopoulos GS. Depression in the elderly. Lancet. 2005;365 (9475):1961-1970. doi:10.1016/S0140-6736(05)66665-2

71. Carvalho AF, Sharma MS, Brunoni AR, Vieta E, Fava GA. The safety, tolerability and risks associated with the use of newer generation antidepressant drugs: a critical review of the literature. Psychother Psychosom. 2016;85(5):270-288. doi:10.1159/000447034

72. Li DX, Wang CN, Wang Y, et al. NLRP3 inflammasome-dependent pyroptosis and apoptosis in hippocampus neurons mediates depressive-like behavior in diabetic mice. Behav Brain Res. 2020;391:112684. doi:10.1016/j.bbr.2020.112684

73. Tian DD, Wang M, Liu A, et al. Antidepressant effect of paeoniflorin is through inhibiting pyroptosis CASP-11/GSDMD pathway. Mol Neurobiol. 2021;58(2):761-776. doi:10.1007/s12035020-02144-5

74. Yang F, Zhu W, Cai X, et al. Minocycline alleviates NLRP3 inflammasome-dependent pyroptosis in monosodium glutamateinduced depressive rats. Biochem Biophys Res Commun. 2020;526(3):553-559. doi:10.1016/j.bbrc.2020.02.149

75. Li Y, Song W, Tong Y, et al. Isoliquiritin ameliorates depression by suppressing NLRP3-mediated pyroptosis via miRNA-27a/ SYK/NF- $\kappa$ B axis. $J$ Neuroinflammation. 2021;18(1):1. doi:10.11 86/s12974-020-02040-8

76. Li X, Sun R, Liu R. Natural products in licorice for the therapy of liver diseases: progress and future opportunities. Pharmacol Res. 2019;144:210-226. doi:10.1016/j.phrs.2019.04.025

77. Fiore C, Eisenhut M, Krausse R, et al. Antiviral effects of Glycyrrhiza species. Phytother Res. 2008;22(2):141-148. doi:10. 1002/ptr.2295

78. Sun ZG, Zhao TT, Lu N, Yang YA, Zhu HL. Research progress of glycyrrhizic acid on antiviral activity. Mini Rev Med Chem. 2019;19(10):826-832. doi:10.2174/138955751966619011 9111125

79. Sumida Y, Yoneda M. Current and future pharmacological therapies for NAFLD/NASH. J Gastroenterol. 2018;53(3):362-376. doi:10.1007/s00535-017-1415-1

80. Younossi Z, Anstee QM, Marietti M, et al. Global burden of NAFLD and NASH: trends, predictions, risk factors and prevention. Nat Rev Gastroenterol Hepatol. 2018;15(1):11-20. doi:10. 1038/nrgastro.2017.109

81. Mridha AR, Wree A, Robertson AAB, et al. NLRP3 inflammasome blockade reduces liver inflammation and fibrosis in experimental NASH in mice. J Hepatol. 2017;66(5):1037-1046. doi:10. 1016/j.jhep.2017.01.022
82. Wan X, Xu C, Yu C, Li Y. Role of NLRP3 inflammasome in the progression of NAFLD to NASH. Can J Gastroenterol Hepatol. 2016;2016:6489012. doi:10.1155/2016/6489012

83. Knorr J, Wree A, Tacke F, Feldstein AE. The NLRP3 inflammasome in alcoholic and nonalcoholic steatohepatitis. Semin Liver Dis. 2020;40(3):298-306. doi:10.1055/s-0040-1708540

84. Yan T, Wang H, Cao L, et al. Glycyrrhizin alleviates nonalcoholic steatohepatitis via modulating bile acids and meta-inflammation. Drug Metab Dispos. 2018;46(9):1310-1319. doi:10.1124/ dmd.118.082008

85. Liapis CD, Avgerinos ED, Kadoglou NP, Kakisis JD. What a vascular surgeon should know and do about atherosclerotic risk factors. J Vasc Surg. 2009;49(5):1348-1354. doi:10.1016/j. jvs.2008.12.046

86. Wang R, Wu W, Li W, et al. Activation of NLRP3 inflammasome promotes foam cell formation in vascular smooth muscle cells and atherogenesis via HMGB1. J Am Heart Assoc. 2018;7(19): e008596. doi:10.1161/JAHA.118.008596

87. Mounier R, Lobo D, Voulgaropoulos J, et al. The multistep road to ventilator-associated lung abscess: a retrospective study of $\mathrm{S}$. aureus ventilator-associated pneumonia. PLoS One. 2017;12(12): e0189249. doi:10.1371/journal.pone.0189249

88. Yao L, Sun T. Glycyrrhizin administration ameliorates Streptococcus aureus-induced acute lung injury. Int Immunopharmacol. 2019;70:504-511. doi:10.1016/j.intimp.2019.02.046

89. Zhou Y, Wang T, Wang Y, et al. Blockade of extracellular highmobility group box 1 attenuates inflammation-mediated damage and haze grade in mice with corneal wounds. Int Immunopharmacol. 2020;83:106468. doi:10.1016/j.intimp.2020.106468

90. Quigley HA, Broman AT. The number of people with glaucoma worldwide in 2010 and 2020. Br J Ophthalmol. 2006;90(3):262267. doi:10.1136/bjo.2005.081224

91. Weinreb RN, Aung T, Medeiros FA. The pathophysiology and treatment of glaucoma: a review. JAMA. 2014;311(18):19011911. doi:10.1001/jama.2014.3192

92. Chi W, Chen H, Li F, Zhu Y, Yin W, Zhuo Y. HMGB1 promotes the activation of NLRP3 and caspase-8 inflammasomes via NF$\kappa \mathrm{B}$ pathway in acute glaucoma. $J$ Neuroinflammation. 2015;12:137. doi:10.1186/s12974-015-0360-2

93. Ahuja CS, Nori S, Tetreault L, et al. Traumatic spinal cord injuryrepair and regeneration. Neurosurgery. 2017;80(3s):S9-s22. doi:10.1093/neuros/nyw080

94. Moghaddam A, Child C, Bruckner T, Gerner HJ, Daniel V, Biglari B. Posttraumatic inflammation as a key to neuroregeneration after traumatic spinal cord injury. Int J Mol Sci. 2015;16 (4):7900-7916. doi:10.3390/ijms 16047900

95. Su XQ, Wang XY, Gong FT, et al. Oral treatment with glycyrrhizin inhibits NLRP3 inflammasome activation and promotes microglial M2 polarization after traumatic spinal cord injury. Brain Res Bull. 2020;158:1-8. doi:10.1016/j.brainresbull.2020.02.009

96. Wang K, Zhang Y, Cao Y, et al. Glycyrrhetinic acid alleviates acute lung injury by PI3K/AKT suppressing macrophagic Nlrp3 inflammasome activation. Biochem Biophys Res Commun. 2020;532(4):555-562. doi:10.1016/j.bbrc.2020.08.044

97. Hayes MT. Parkinson's disease and parkinsonism. Am J Med. 2019;132(7):802-807. doi:10.1016/j.amjmed.2019.03.001

98. Samii A, Nutt JG, Ransom BR. Parkinson's disease. Lancet. 2004;363 (9423):1783-1793. doi:10.1016/S0140-6736(04)16305-8

99. Haque ME, Akther M, Jakaria M, Kim IS, Azam S, Choi DK. Targeting the microglial NLRP3 inflammasome and its role in Parkinson's disease. Mov Disord. 2020;35(1):20-33. doi:10.1002/ mds. 27874

100. Nizami S, Hall-Roberts H, Warrier S, Cowley SA, Di Daniel E. Microglial inflammation and phagocytosis in Alzheimer's disease: potential therapeutic targets. $B r J$ Pharmacol. 2019;176 (18):3515-3532. doi:10.1111/bph.14618 
101. Yan YQ, Fang Y, Zheng R, Pu JL, Zhang BR. NLRP3 inflammasomes in Parkinson's disease and their regulation by Parkin. Neuroscience. 2020;446:323-334. doi:10.1016/j.neuroscience.2020.08.004

102. Chen CM, Yen CY, Chen WL, et al. Pathomechanism characterization and potential therapeutics identification for Parkinson's disease targeting neuroinflammation. Int J Mol Sci. 2021;22 (3): 1062 .

103. Rheinheimer J, de Souza BM, Cardoso NS, Bauer AC, Crispim D. Current role of the NLRP3 inflammasome on obesity and insulin resistance: a systematic review. Metabolism. 2017;74:19. doi:10.1016/j.metabol.2017.06.002

104. Tack CJ, Stienstra R, Joosten LA, Netea MG. Inflammation links excess fat to insulin resistance: the role of the interleukin-1 family. Immunol Rev. 2012;249(1):239-252. doi:10.1111/j.1600065X.2012.01145.X

105. Vandanmagsar B, Youm YH, Ravussin A, et al. The NLRP3 inflammasome instigates obesity-induced inflammation and insulin resistance. Nat Med. 2011;17(2):179-188. doi:10.1038/ nm. 2279

106. Chen Y, Qian Q, Yu J. Carbenoxolone ameliorates insulin sensitivity in obese mice induced by high fat diet via regulating the IкB- $\alpha / \mathrm{NF}-\kappa \mathrm{B}$ pathway and NLRP3 inflammasome. Biomed Pharmacother. 2019;115:108868. doi:10.1016/j.biopha.2019.108868

107. Yue SJ, Qin YF, Kang A, et al. Total flavonoids of Glycyrrhiza uralensis alleviates irinotecan-induced colitis via modification of gut microbiota and fecal metabolism. Front Immunol. 2021;12:628358. doi:10.3389/fimmu.2021.628358

108. Zou J, Li W, Wang G, et al. Hepatoprotective effects of Huangqi decoction (Astragali Radix and Glycyrrhizae Radix et Rhizoma) on cholestatic liver injury in mice: involvement of alleviating intestinal microbiota dysbiosis. J Ethnopharmacol. 2021;267: 113544. doi:10.1016/j.jep.2020.113544
109. Mangan MSJ, Olhava EJ, Roush WR, Seidel HM, Glick GD, Latz E. Targeting the NLRP3 inflammasome in inflammatory diseases. Nat Rev Drug Discov. 2018;17(8):588-606. doi:10.1038/ $\operatorname{nrd} .2018 .97$

110. Zhang X, Xu A, Lv J, et al. Development of small molecule inhibitors targeting NLRP3 inflammasome pathway for inflammatory diseases. Eur J Med Chem. 2020;185:111822. doi:10.10 16/j.ejmech.2019.111822

111. Wang $\mathrm{Z}, \mathrm{Xu} \mathrm{G}$, Gao Y, et al. Cardamonin from a medicinal herb protects against LPS-induced septic shock by suppressing NLRP3 inflammasome. Acta Pharm Sin B. 2019;9(4):734-744. doi:10.1016/j.apsb.2019.02.003

112. Liu H, Zhan X, Xu G, et al. Cryptotanshinone specifically suppresses NLRP3 inflammasome activation and protects against inflammasome-mediated diseases. Pharmacol Res. 2021;164: 105384. doi:10.1016/j.phrs.2020.105384

113. Shi W, Xu G, Zhan X, et al. Carnosol inhibits inflammasome activation by directly targeting HSP90 to treat inflammasomemediated diseases. Cell Death Dis. 2020;11(4):252. doi:10.1038/ s41419-020-2460- $\mathrm{x}$

114. Qin N, Xu G, Wang Y, et al. Bavachin enhances NLRP3 inflammasome activation induced by ATP or nigericin and causes idiosyncratic hepatotoxicity. Front Med. 2021;15(4):594-607. doi:10. 1007/s11684-020-0809-2

115. Wang Z, Xu G, Wang H, et al. Icariside II, a main compound in Epimedii Folium, induces idiosyncratic hepatotoxicity by enhancing NLRP3 inflammasome activation. Acta Pharm Sin B. 2020;10(9):1619-1633. doi:10.1016/j.apsb.2020.03.006

116. Wang Z, Xu G, Zhan X, et al. Carbamazepine promotes specific stimuli-induced NLRP3 inflammasome activation and causes idiosyncratic liver injury in mice. Arch Toxicol. 2019;93 (12):3585-3599. doi:10.1007/s00204-019-02606-3
Journal of Inflammation Research

\section{Publish your work in this journal}

The Journal of Inflammation Research is an international, peerreviewed open-access journal that welcomes laboratory and clinical findings on the molecular basis, cell biology and pharmacology of inflammation including original research, reviews, symposium reports, hypothesis formation and commentaries on: acute/chronic inflammation; mediators of inflammation; cellular processes; molecular

\section{Dovepress}

mechanisms; pharmacology and novel anti-inflammatory drugs; clinical conditions involving inflammation. The manuscript management system is completely online and includes a very quick and fair peerreview system. Visit http://www.dovepress.com/testimonials.php to read real quotes from published authors. 